\title{
Open subpectoral biceps tenodesis in patients over 65 does not result in an increased rate of complications
}

Andreas Voss ${ }^{1,2^{*}+}$, Simone Cerciello ${ }^{3,4 \dagger}$, Jessica DiVenere ${ }^{1}$, Olga Solovyova ${ }^{5}$, Felix Dyrna ${ }^{1}$, John Apostolakos ${ }^{1}$, David Lam¹, Mark P. Cote', Knut Beitzel ${ }^{2}$ and Augustus D. Mazzocca' ${ }^{1}$

\begin{abstract}
Background: Long head biceps tendon pathology is a common cause of anterior shoulder pain and is often associated with other shoulder conditions, such as rotator cuff tears and osteoarthritis. It is well accepted that older patients are at increased risk for major and minor peri- and postoperative complications.

The purpose of this study is to investigate patients over 65 years old who underwent subpectoral biceps tenodesis and compare the complication rates of this group to those of patients younger than 65 years old. The hypothesis is, that there would be no difference in complication rates and that clinical outcome scores for patients over 65 were satisfying and showed improvements over time.
\end{abstract}

Methods: There were 337 patients who underwent open subpectoral biceps tenodesis, between January 2005 and June 2015, 23 were identified as being over the age of 65 with a minimum follow up of 12 months. All patients over the age of 65 were evaluated pre- and postoperatively using Simple Shoulder Test (SST), American Shoulder and Elbow Surgeons (ASES), Constant-Murley (CM) and Single Assessment Numeric Evaluation (SANE). Intraoperative and postoperative adverse events (fracture, infection, wound opening, rupture/failure and neurovascular injuries) related to the tenodesis procedure and to the surgery itself were collected from all 337 patients in a routine postoperative follow-up.

Results: The under 65 group (range 27-64 years) at an average follow up (FU) of 30 months (range 12-91 months) showed a 5.4\% (17 out of 314) post-operative complication rate related to the subpectoral tenodesis, whereas the group over 65 (range 65-77 years) at an average follow up of 33 months (range 12-79 months) showed an 8.7\% (2 out of 23) complication rate.

Conclusion: This study demonstrates that in patients over the age of 65 , biceps tenodesis is a successful procedure when performed for biceps tendinopathy and concomitantly with other surgical procedures of the shoulder, and does not result in an increased rate of complications when compared to a group of patients under the age of 65 .

Keywords: Shoulder, Subpectoral, Biceps, Tenodesis, Open tenodesis, Over 65

\footnotetext{
* Correspondence: a.voss@tum.de

${ }^{\dagger}$ Equal contributors

'Department of Orthopaedic Surgery, University of Connecticut Health

Center, Farmington, CT, USA

${ }^{2}$ Department of Orthopaedic Sports Medicine, Technical University of

Munich, Munich, Germany

Full list of author information is available at the end of the article
} International License (http://creativecommons.org/licenses/by/4.0/), which permits unrestricted use, distribution, and reproduction in any medium, provided you give appropriate credit to the original author(s) and the source, provide a link to the Creative Commons license, and indicate if changes were made. The Creative Commons Public Domain Dedication waiver (http://creativecommons.org/publicdomain/zero/1.0/) applies to the data made available in this article, unless otherwise stated. 


\section{Background}

Long head biceps tendon (LHB) pathology is a common cause of anterior shoulder pain and is often associated with other shoulder conditions [1-4]. Therefore, biceps tenodesis is a common and well accepted procedure. The main purpose is to restore the physiological shape of the upper limp and to avoid postoperative cramping of the biceps muscle, as a known symptom after tenotomy. According to Giphart et al. [5] there is no significant difference in motion after a tenotomy compared to intact biceps tendon.

It is well accepted that patients over the age of 65 are at increased risk for major and minor peri- and postoperative complications [6-11]. Although there are no studies that correlate the rate of complications in biceps tenodesis to age, based on the above mentioned data, it seems reasonable to infer that this procedure may have a greater rate of complications with increasing age as well. Risks of fracture during drilling and insertion of the interference screw, wound complications, and venous thromboembolic disease are of particular concern.

Though the evidence is mixed a greater incidence of wound infections in older patients has been described in the literature [12-15], as well as several case reports describing proximal humerus fracture during subpectoral biceps tenodesis $[16,17]$. Due to the concern regarding increased rates of complications in older patients, some surgeons elect to perform only biceps tenotomies in these patients. The limited evidence in the literature, reports comparable outcomes for biceps tenodesis versus tenotomy [18-23], though studies show that patients treated with tenotomies have greater incidence of postoperative cramping and cosmetic deformity [18-21, 23].

To our knowledge, there is no published literature evaluating the complications and outcomes of biceps tenodesis in patients older than 65 . Therefore, the purpose of this study was to retrospectively evaluate prospectively collected clinical outcomes data in patients over 65 years old who underwent subpectoral biceps tenodesis, to report their clinical outcome data and to compare the complication rates to those of patients younger than 65 years old who had the same procedure performed. Our hypothesis is that there would be no difference in adverse events among patients over 65 . Furthermore, we hypothesized, that clinical outcome scores were satisfying and showed improvements over time.

\section{Methods}

This is a retrospective case series of prospectively collected data of all patients 65 or older who underwent open subpectoral biceps tenodesis with an interference screw fixation, between 2005 and June 2015, in a singles surgeon's practice $(n=380)$. Patients were identified through an outcome registry query (IRB\# IE-13-151-1). Patients undergoing concomitant arthroplasty, resurfacing procedure, or revision procedures were excluded (n.43).

All patients were included in the decision process of the surgical procedure regarding tenotomy vs. tenodesis and the patient made the final decision. Indication for tenodesis in patients over 65 years old include: Chronic atrophic changes in the LHBT, painful and therapy resistant tenosynovitis, symptomatic intra-articular partial tears $(>25 \%)$ of the LHBT, additional treatment during rotator cuff repair surgery, pulley lesion with biceps instability (subluxation and luxation), SLAP lesion in elderly patients, painful and hyperthrophic LHBT with secondary impingement and subpectoral biceps pain. Contraindications for subpectoral biceps tenodesis were: obesity, diabetes, highly osteoporotic bone, increased cardio vascular morbidity, tumor at the proximal humerus and patient with implants (e.g.: plates and nails). Obesity was defined according to the WHO (BMI $\geq 30$ ). Patients who presented with documented back pain, caused by a fractured or collapsed vertebra, loss of height over time, a bone fracture from standing height or a diagnosed osteoporosis through bone mineral density measurements were not eligible for subpectoral biceps tenodesis.

Outcome measures including the Simple Shoulder Test (SST), American Shoulder and Elbow Surgeons (ASES), Constant-Murley (CM) and Single Assessment Numeric Evaluation (SANE) were prospectively collected preoperatively and postoperatively in all patients over the age of 65 , including adverse events and postoperative complications. All patients below 65 have been seen and evaluated on a regular basis to determine if any adverse event or postoperative complications occurred, but complete postoperative outcome data (SST, ASES, CM and SANE) was not obtained for all patients. Adverse events including death, venous thromboembolic disease, intraoperative and/or postoperative fracture, intraoperative nerve or vessel damage, superficial and deep surgical site infections, wound dehiscence, repair failure and large postoperative hematoma. Additional information abstracted from the medical record included indications for primary procedure, e.g. persistent pain and shoulder stiffness.

\section{Surgical technique [24]}

After arthroscopic tenotomy of the LHBT, the skin incision is followed by a safe blunt dissection of the pectoralis major tendon until the bicipital groove and the long head of the biceps tendon are exposed. The LHBT is then stitched starting $2 \mathrm{~cm}$ from the musculotendinous junction for $2 \mathrm{~cm}$. A guide pin is used to drill a unicortical hole in the ventral aspect of the cortex within 
the bicipital groove, followed by an $8-\mathrm{mm}$ unicortical reamer. After unicortical drilling an 8-mm tap is used to prepare the cortex. One of the stiches end is then loaded through the biceps tenodesis screwdriver, the other end is left free. An 8-mm screw is deployed along with the tendon into the previously drilled $8 \mathrm{~mm}$ hole till the screw is flush with the humeral cortex. The two ends of the suture are then tied over the screw securing the screw in place.

\section{Statistical analysis}

Descriptive statistics to characterize the study group were calculated using means and standard deviation or frequency and proportion where appropriate. No power analysis has been performed because this study is a sample of convenience. Difference between the preand postoperative outcome scores in patients $\geq 65$ years of age were compared with a paired $t$ test. Rates of adverse events were compared between patients $\geq 65$ and $<65$ years of age with Fischer's exact test. The alpha level for all comparisons was set at 0.05 using Stata 12 (StataCorp. 2011. Stata Statistical Software: Release 12. College Station, TX: StataCorp LP).

\section{Results}

This search resulted in 337 patients of whom 314 patients were included in the under 65 years group and 23 in the over 65 group. The study group consisted of 23 patients (Table 1). The average age at time of surgery was 69.7 years (range 65-77) and the average length of follow-up was 33 months (range 12-79). Biceps tenodesis was associated with a concomitant procedure in all cases (Fig. 1). Two patients (8.7\%) had biceps related complications including one biceps tendonitis and one LHB rupture. Three patients $(13 \%)$ had postoperative complications not strictly related to the tenodesis itself. One developed a wound infection related to the rotator cuff repair, which required arthroscopic irrigation and debridement and antibiotics; the infection resolved, and the patient went on to have no

Table 1 Descriptive data of included study population with additional clinical scores for patients over the age of 65

\begin{tabular}{|c|c|c|c|}
\hline & Over 65 yrs & Under 65 yrs & $P$ value \\
\hline Number of patients & 23 & 314 & \\
\hline Average age & 69.7 & 50 & \\
\hline Average lenght of FU (months) & 33 & 30 & \\
\hline $\begin{array}{l}\% \text { of complications related to } \\
\text { the tenodesis itself }\end{array}$ & $8.3 \%$ & $5.4 \%$ & ns \\
\hline $\begin{array}{l}\% \text { of complications not related } \\
\text { to the tenodesis itself }\end{array}$ & $12.5 \%$ & $31.2 \%$ & \\
\hline Increase in ASES score & 45.6 & na & $p<0.001$ \\
\hline Increase in Constant score & 52.2 & na & $p<0.001$ \\
\hline Increase in SST & 5.0 & na & $p<0.001$ \\
\hline
\end{tabular}

further sequelae and excellent outcomes. Two patients developed a postoperative adhesive capsulitis, related to rotator cuff repair, which resolved with appropriate physical therapy (Table 2). There were no incidences of death, intraoperative fracture, intraoperative nerve or vessel damage, repair failure, or persistent pain.

In the under 65 cohort $(n=314)$ the average age at the time of surgery was 50 years (range 29-64) and the average FU was 30 months (range 12-91 months). Biceps tenodesis was performed as an isolated procedure in 5 cases or in association with other procedures in 309 cases (see flowchart diagram). Seventeen patients (5.4\%) had complications related to the tenodesis itself (hematoma, granuloma, infection, rupture, pain over the tenodesis). Thirty-eight patients (12.1\%) had persistent pain (variable location), 48 (15.3\%) had complications related to the cuff repair (adhesive capsulitis, weakness, failure), and 12 (3.8\%) had various complications (tingling, post traumatic fracture) (Tab. 2). There were no incidences of death, intraoperative fracture, or intraoperative nerve or vessel damage. The difference in complication rates between the under and over 65 years groups was not statistically significant $(p=0.23)$.

Pre- and postoperative outcomes in the older than 65 group were assessed. The mean pre- and postoperative ASES scores were $45.1( \pm 19.9)$ and $90.8( \pm 16.2)$, respectively. The SST score increased from $5.6( \pm 3.1)$ to 10.6 $( \pm 2.2)$, the CM increased from $37.0( \pm 13.8)$ to 89.2 $( \pm 9.0)$ and the post-operative SANE score showed good results with a mean of $89.6( \pm 15.3)$. All of these improvements were statistically significant $(p<0.001)$.

\section{Discussion}

The most important finding of the present study is the comparable specific complication rate of subpectoral tenodesis in patients older (8.7\%) and younger (5.4\%) than 65 years. The general rate of complications was $21.7 \%$ in the over 65 years cohort and $36.6 \%$ in the under 65 years group. Moreover, the functional outcomes are encouraging with significant improvement in all examined tools (ASES, SST, CM and SANE). The outcomes are comparable to those reported in recent studies on younger patients with persistent pain having been reported in up to $50 \%$ of patients. $[25,26]$.

These findings are particularly interesting since they may help change the management of biceps pathology in this older cohort of patients. In fact, it is well established that pathology of the LHB either traumatic or degenerative is a common cause of anterior shoulder pain [27], and operative treatment options include tenotomy or tenodesis. Historically biceps tenotomy has been proposed in older patients (over 65 years) or in case of low-demanding activities [20, 28]. This approach had two explanations. From one side the orthopaedic literature highlighted that increasing age, increased the risk of morbidity and 


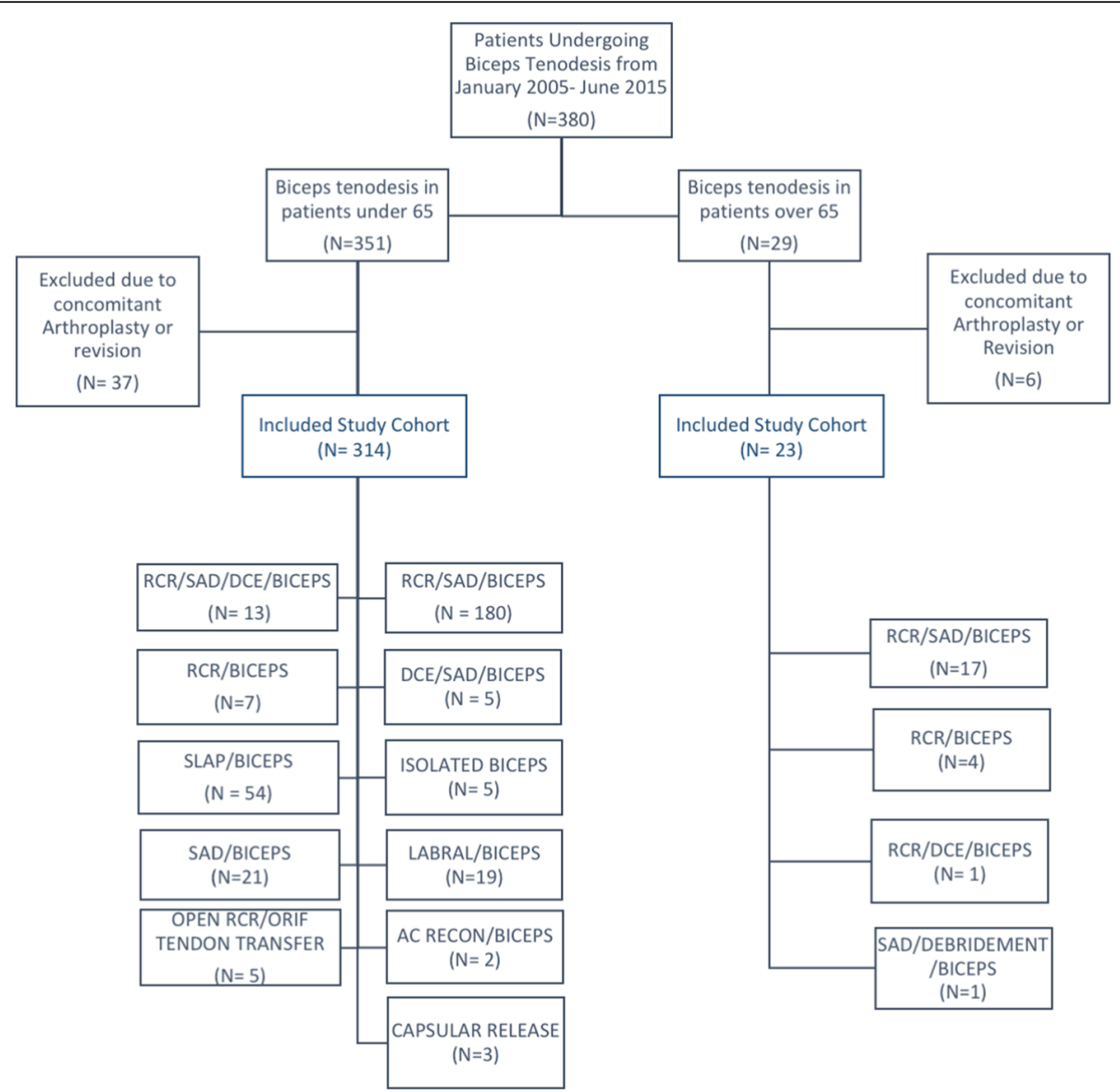

Fig. 1 Flowchart showing inclusion and exclusion of the study population

mortality in operated patients, particularly that of fracture, wound infection, and venous thromboembolic disease $[1,6-15,29-32]$. From the other, it is well established that tenotomy requires reduced immobilization with reduced adverse side effects and postoperative rehabilitation with decreased risk of postoperative stiffness. However, the drawback of this option is the increased incidence of postoperative cramping and poor cosmesis [18-21, 23, 27]. Conversely, tenodesis has been generally performed in younger and more active subjects. Subpectoral fixation has been initially described [33] to reduce the rate of postoperative pain traditionally associated with arthroscopic techniques [34]. This seems related to the more distal tenodesis site achievable with subpectoral tenodesis [35].

Unfortunately, a variable spectrum of complications has been described including failure or re-rupture of the tendon, hematoma, infection, persistent pain, reaction to a fixation device, nerve injury, cosmetic deformity, and fracture [36, 37]. Humeral fractures have been observed with cortical screws $[16,17]$ as a consequence of the reduced bone resistance when a hole is drilled [38]. Euler et al. have demonstrated a correlation with laterally eccentric

Table 2 Overview of complications related to the subpectoral tenodesis in both over and under 65 years

\begin{tabular}{|c|c|c|c|c|c|c|}
\hline & Over 65 yrs & & & Under 65 yrs & & \\
\hline Patients & 23 & & & 314 & & \\
\hline \multirow[t]{2}{*}{$\begin{array}{l}\text { Complications related to the } \\
\text { tenodesis }\end{array}$} & n.2 (8.7\%) & LHB tendonitis & n.1 (4.3\%) & n.17 (5.4\%) & $\begin{array}{l}\text { hematoma, granuloma, infection, } \\
\text { rupture, pain over the tenodesis }\end{array}$ & n.17 (5.4\%) \\
\hline & & LHB rupture & n.1 (4.3\%) & & & \\
\hline \multirow{3}{*}{$\begin{array}{l}\text { Complications not related to } \\
\text { the tenodesis }\end{array}$} & n.3 (13\%) & Adhesive capsulitis & n.2 (8.7\%) & n.98 (31.2\%) & Persistent pain & n.38 (12.1\%) \\
\hline & & Wound infection & n.1 (4.3\%) & & $\begin{array}{l}\text { adhesive capsulitis, weakness, } \\
\text { failure }\end{array}$ & n.48 (15.3\%) \\
\hline & & & & & tingling, post traumatic fracture & n.12 (3.8\%) \\
\hline
\end{tabular}


screws [39]. This risk is even higher in old patients with reduced bone mineral density (BMD). According to these evidences, the best treatment option of pathologic LHB is still debated, especially in older patients. This study is comparing the complications rates of LHB subpectoral tenodesis with screw fixation in patients with more than 65 years and less than 65 years. In addition, functional outcomes in the over 65 years cohort were reported. All patients had the same surgical technique performed by the same senior surgeon. In addition, although the analysis of the data was retrospective they were prospectively collected by an independent surgeon. The difference in rates of complications strictly related to LHB tenodesis between the two groups $(8.7 \%$ in the older group vs $5.4 \%$ in the younger group was not statistically significant $(p=0.23)$. This data is however higher than what has been reported by Rios et al. (3\%) [40], and Nho et al. (2\%) [41]. General complications rate was higher in both groups with the majority of them being persistent pain or complications related to concomitant procedures such as cuff repair (adhesive capsulitis, weakness, failure of the repair. However major adverse effects such as deaths, intraoperative fractures, intraoperative nerve or vessel damage were not observed. The reasonable for his difference might be multifarious and related the accompanied primary surgical rotator cuff repair. Therefore, a greater degree of tendon retraction, the surgical reconstruction of massive cuff tears compared to single tendon ruptures or the general morbidity of the population presented in our department might influence the rate. In addition to complications, clinical outcomes in the older patient group were evaluated. Statistically significant improvement across all outcome measures collected was observed with final ASES being $90.8( \pm 16.2)$, SST score $10.6( \pm 2.2)$ and CM increased $89.6( \pm 9.0)$. In addition, the mean postoperative SANE was 89.9 ( \pm 15.3$)$., indicating a high level of satisfaction with the outcome of the procedure. These data were similar to those reported in previous series on isolated subpectoral tenodesis [42, 43]. In the series by Mazzocca et al. at an average FU of 29 months, mean ConstantMurley score was 90.2, ASES score was 89.2, SST score 10.6, and SANE score 86.9\% [43]. Werner et al. reported similar results at an average FU of 3.3 years with a mean Constant-Murley score of 91.8, ASES score of 88.4, SST score of 10.6, and SANE score of $86.8 \%$ [42]. Though many surgeons believe that a patient age over 65 is a contraindication to biceps tenodesis, the present study did not show an increased incidence of complications in this specific patient population whereas confirm the satisfactory outcomes previously reported in younger patients.

Several limitations were identified during the course of this study. Firstly, the retrospective design has inherent limitations due to the inability to randomize the sample and manipulate the independent variable. Secondly there are unequal sample sizes between the group of interest and the younger age group. This was due to the distribution of the patients see in our clinic and operated on. Thirdly, the cohort of patients over the age of 65 is relatively small. As there are little reports on outcomes and complications in this patient population, we believe that this is a meaningful contribution to the literature. Finally, as the biceps tenodesis procedure was a concomitant procedure in most cases, it is impossible to distinguish the amount of clinical improvement that can be attributed to the biceps procedure. However, we believe that if patients continued to have pain or limitations due to their biceps tendon, it would be reflected in their postoperative clinical outcomes.

\section{Conclusion}

This study demonstrates that in patients over the age of 65 , biceps tenodesis is a successful procedure when performed for biceps tendinopathy and concomitantly with other surgical procedures of the shoulder, and does not result in an increased rate of complications when compared to a group of patients under the age of 65 . In addition, the functional outcomes are comparable to those reported in recent studies on younger cohorts.

\section{Abbreviations}

ASES: American shoulder and elbow surgeons; BMD: Bone mineral density; CM: Constant-Murley; FU: Follow up; IRB: Institutional review board; LHB: Long head biceps tendon; SANE: Single assessment numeric evaluation; SST: Simple shoulder test

\section{Acknowledgements}

None.

\section{Funding}

The University of Connecticut Health Center/UConn Musculoskeletal Institute has received research funding for this study from Arthrex Inc. (Naples. Fl). The company had no influence on study design, data collection, interpretation of the results, or the final manuscript. This work was supported by the German Research Foundation (DFG) and the Technische Universität München within the funding programme Open Access Publishing.

Availability of data and materials

The datasets generated and analyzed during the current study are not publicly available due professional discretion, as they were part of patient's records, but are available as de-identified data sheet from the corresponding author on reasonable request.

\section{Authors' contributions}

AV Principle investigator, data analysis, substantial contributions to the conception or design of the work, SC Substantial contributions to the conception or design of the work, major contribution to discussion. JD Data analysis, patient record management (paper files), OS Data analysis, patient record management (online files), FD Revising the work critically for important intellectual content. JA Data analysis, patient record management (online files), native language corrections. DL Data analysis, patient record management (paper files), MC Independent data analysis to verify the result from principle investigator. KB Revising the work critically for important intellectual content, data analysis. ADM Final approval of the version to be published. The authors attest that the manuscript has been read and a proved by all authors, and each author believes that the manuscript represents honest work. All authors read and approved the final manuscript. 


\section{Ethics approval and consent to participate}

This study was approved by the UConn Health Institutional Review Board IRB Number: IE-13-151-1. This was a retrospective review of prospectively collected data the IRB gave permission to collect this data. No consent was needed.

\section{Consent for publication}

No consent for publication was needed, because of the de-identified data, as part of the routine clinical follow-up, which patients undergo after their surgery.

\section{Competing interests}

The following authors declare that they have no competing interests: SC, JD, OS, FD, JA, DL, MC. The following authors declare that they have competing interests: AV received finical support from the German Research Foundation (DFG) and the Technische Universität München for publication of this manuscript (processing fee). KB, ADM are consultants for Arthrex Inc., (Naples, Fl, USA), ADM received research funding from Arthrex Inc., (Naples, $\mathrm{Fl}$, USA). None of the authors have non-financial competing interests.

\section{Publisher's Note}

Springer Nature remains neutral with regard to jurisdictional claims in published maps and institutional affiliations.

\section{Author details}

'Department of Orthopaedic Surgery, University of Connecticut Health Center, Farmington, CT, USA. ${ }^{2}$ Department of Orthopaedic Sports Medicine, Technical University of Munich, Munich, Germany. ${ }^{3}$ Department of Orthopaedic Surgery, Casa di Cura Villa Betania, Rome, Italy. ${ }^{4}$ Department of Orthopaedic Surgery, Marrelli Hospital, Crotone, Italy. ${ }^{5}$ Department of Orthopaedic Surgery, NYU Hospital for Joint Disesases, New York, NY, USA.

\section{Received: 23 May 2017 Accepted: 11 October 2017}

\section{Published online: 06 November 2017}

\section{References}

1. Della Rocca GJ, Leung KS, Pape HC. Periprosthetic fractures: epidemiology and future projections. J Orthop Trauma. 2(25 Suppl):S66-70.

2. Gill TJ, Mclrvin E, Mair SD, Hawkins RJ. Results of biceps tenotomy for treatment of pathology of the long head of the biceps brachii. J Shoulder Elb Surg. 2001;10:247-9.

3. Ide J, Maeda S, Takagi KA. Comparison of arthroscopic and open rotator cuff repair. Arthroscopy. 2005;21:1090-8.

4. Scheibel M, Schroder RJ, Chen J, Bartsch M. Arthroscopic soft tissue tenodesis versus bony fixation anchor tenodesis of the long head of the biceps tendon. Am J Sports Med. 2011;39:1046-52.

5. Giphart JE, Elser F, Dewing CB, Torry MR, Millett PJ. The long head of the biceps tendon has minimal effect on in vivo glenohumeral kinematics: a biplane fluoroscopy study. Am J Sports Med. 2012;40:202-12.

6. Acosta FLJ, McClendon JJ, O'Shaughnessy BA, et al. Morbidity and mortality after spinal deformity surgery in patients 75 years and older: complications and predictive factors. J Neurosurg Spine. 15:667-74.

7. Daubs MD, Lenke LG, Cheh G, Stobbs G, Bridwell KH. Adult spinal deformity surgery: complications and outcomes in patients over age 60. Spine (Phila Pa 1976). 2007;32:2238-44.

8. Easterlin MC, Chang DG, Talamini M, Chang DC. Older age increases short-term surgical complications after primary knee arthroplasty. Clin Orthop Relat Res.

9. Schoenfeld AJ, Carey PA, Cleveland AW 3rd, Bader JO, Bono CM. Patient factors, comorbidities, and surgical characteristics that increase mortality and complication risk after spinal arthrodesis: a prognostic study based on 5,887 patients. Spine J.

10. Schoenfeld AJ, Ochoa LM, Bader JO, Belmont PJJ. Risk factors for immediate postoperative complications and mortality following spine surgery: a study of 3475 patients from the National Surgical Quality Improvement Program. J Bone Joint Surg Am. 93:1577-82.

11. Lindahl H, Malchau H, Oden A, Garellick G. Risk factors for failure after treatment of a periprosthetic fracture of the femur. J Bone Joint Surg Br. 2006;88:26-30.

12. Carroll K, Dowsey M, Choong P, Peel T. Risk factors for superficial wound complications in hip and knee arthroplasty. Clin Microbiol Infect.
13. Dale H, Skramm I, Lower HL, et al. Infection after primary hip arthroplasty: a comparison of 3 Norwegian health registers. Acta Orthop. 82:646-54.

14. Veeravagu A, Patil CG, Lad SP, Boakye M. Risk factors for postoperative spinal wound infections after spinal decompression and fusion surgeries. Spine (Phila Pa 1976). 2009;34:1869-72.

15. Ridgeway S, Wilson J, Charlet A, Kafatos G, Pearson A, Coello R. Infection of the surgical site after arthroplasty of the hip. J Bone Joint Surg Br. 2005;87:844-50.

16. Reiff SN, Nho SJ, Romeo AA. Proximal humerus fracture after keyhole biceps tenodesis. Am J Orthop (Belle Mead NJ). 39:E61-3.

17. Sears BW, Spencer EE, Getz CL. Humeral fracture following subpectoral biceps tenodesis in 2 active, healthy patients. J Shoulder Elb Surg. 20:e7-11.

18. Boileau P, Baque F, Valerio L, Ahrens P, Chuinard C, Trojani C. Isolated arthroscopic biceps tenotomy or tenodesis improves symptoms in patients with massive irreparable rotator cuff tears. J Bone Joint Surg Am. 2007;89:747-57.

19. Delle Rose G, Borroni M, Silvestro A, et al. The long head of biceps as a source of pain in active population: tenotomy or tenodesis? A comparison of 2 case series with isolated lesions. Musculoskelet Surg. 1 (96 Suppl):S47-52.

20. Frost A, Zafar MS, Maffulli N. Tenotomy versus tenodesis in the management of pathologic lesions of the tendon of the long head of the biceps brachii. Am J Sports Med. 2009;37:828-33.

21. Hsu AR, Ghodadra NS, Provencher MT, Lewis PB, Bach BR. Biceps tenotomy versus tenodesis: a review of clinical outcomes and biomechanical results. J Shoulder Elb Surg. 20:326-32.

22. Osbahr DC, Diamond AB, Speer KP. The cosmetic appearance of the biceps muscle after long-head tenotomy versus tenodesis. Arthroscopy. 2002;18:483-7.

23. Slenker NR, Lawson K, Ciccotti MG, Dodson CC, Cohen SB. Biceps tenotomy versus tenodesis: clinical outcomes. Arthroscopy. 28:576-82.

24. Voss A, Cerciello S, Yang J, Beitzel K, Cote MP, Mazzocca AD. Open subpectoral Tenodesis of the proximal biceps. Clin Sports Med. 2016;35:137-52.

25. Friedman $J$ L, FitzPatrick JL, Rylander LS, Bennett C, Vidal AF, McCarty EC. Biceps Tenotomy versus Tenodesis in active patients younger than 55 years: is there a difference in strength and outcomes? Orthop J Sports Med. 2015: 3:2325967115570848.

26. Gombera MM, Kahlenberg CA, Nair R, Saltzman MD, Terry MA. Allarthroscopic suprapectoral versus open subpectoral tenodesis of the long head of the biceps brachii. Am J Sports Med. 2015;43:1077-83.

27. Friedman DJ, Dunn JC, Higgins LD, Warner JJ. Proximal biceps tendon: injuries and management. Sports Med Arthrosc Rev. 2008;16:162-9.

28. Slenker NR, Lawson K, Ciccotti MG, Dodson CC, Cohen SB. Biceps tenotomy versus tenodesis: clinical outcomes. Arthroscopy. 2012;28:576-82.

29. Lubbeke A, Roussos C, Barea C, Kohnlein W, Hoffmeyer P. Revision total hip arthroplasty in patients 80 years or older. J Arthroplast. 27:1041-6.

30. Meek RM, Norwood T, Smith R, Brenkel IJ, Howie CR. The risk of periprosthetic fracture after primary and revision total hip and knee replacement. J Bone Joint Surg Br. 93:96-101.

31. Singh JA, Jensen MR, Harmsen SW, Lewallen DG. Are gender, comorbidity, and obesity risk factors for postoperative periprosthetic fractures after primary total hip arthroplasty? J Arthroplasty. 28:126-131 e121-122

32. CC W, MK A, SS W, Lin LC. Risk factors for postoperative femoral fracture in cementless hip arthroplasty. J Formos Med Assoc. 1999;98:190-4.

33. Mazzocca AD, Rios CG, Romeo AA, Arciero RA. Subpectoral biceps tenodesis with interference screw fixation. Arthroscopy. 2005;21:896.

34. Lutton DM, Gruson Kl, Harrison AK, Gladstone JN, Flatow EL. Where to tenodese the biceps: proximal or distal? Clin Orthop Relat Res. 2011;469:1050-5.

35. Johannsen AM, Macalena JA, Carson EW, Tompkins M. Anatomic and radiographic comparison of arthroscopic suprapectoral and open subpectoral biceps tenodesis sites. Am J Sports Med. 2013;41:2919-24.

36. Mazzocca AD, Bicos J, Santangelo S, Romeo AA, Arciero RA. The biomechanical evaluation of four fixation techniques for proximal biceps tenodesis. Arthroscopy. 2005;21:1296-306.

37. Provencher MT, LeClere LE, Romeo AA. Subpectoral biceps tenodesis. Sports Med Arthrosc Rev. 2008:16:170-6.

38. Ho KW, Gilbody J, Jameson T, Miles AW. The effect of $4 \mathrm{~mm}$ bicortical dril hole defect on bone strength in a pig femur model. Arch Orthop Trauma Surg. 2010;130:797-802.

39. Euler SA, Smith SD, Williams BT, Dornan GJ, Millett PJ, Wijdicks CA. Biomechanical analysis of subpectoral biceps tenodesis: effect of screw malpositioning on proximal humeral strength. Am J Sports Med. 2015;43:69-74. 
40. Rios D MgF, Horan MP, Millett PJ. Complications following subpectoral biceps tenodesis with interference screw fixation. J Shoulder Elb Surg. 2013;22:e26.

41. Nho SJ, Reiff SN, Verma NN, Slabaugh MA, Mazzocca AD, Romeo AA. Complications associated with subpectoral biceps tenodesis: low rates of incidence following surgery. J Shoulder Elbow Surg. 2010;19:764-8.

42. Werner BC, Evans CL, Holzgrefe RE, et al. Arthroscopic suprapectoral and open subpectoral biceps tenodesis: a comparison of minimum 2-year clinical outcomes. Am J Sports Med. 2014;42:2583-90.

43. Mazzocca AD, Cote MP, Arciero CL, Romeo AA, Arciero RA. Clinical outcomes after subpectoral biceps tenodesis with an interference screw. Am J Sports Med. 2008;36:1922-9.

Submit your next manuscript to BioMed Central and we will help you at every step:

- We accept pre-submission inquiries

- Our selector tool helps you to find the most relevant journal

- We provide round the clock customer support

- Convenient online submission

- Thorough peer review

- Inclusion in PubMed and all major indexing services

- Maximum visibility for your research

Submit your manuscript at www.biomedcentral.com/submit 